\title{
8 Research Square

\section{Nonpoint Source Pollution (NPSP) Induces Structural and Functional Variation in the Fungal Community of Sediments in the Jialing River, China}

Fei $X u$

China West Normal University

Lanping Zhu

China West Normal University

Jiaying Wang

China West Normal University

\section{Yuqin Xue}

China West Normal University

Kunhe Liu

China West Normal University

Fubin Zhang

China West Normal University

TUO ZHANG ( $\nabla$ xiaotuodujiang@126.com )

China West Normal University https://orcid.org/0000-0001-9412-7050

\section{Research Article}

Keywords: Jialing River, NPSP, fungi, community structure, function prediction

Posted Date: December 1st, 2021

DOI: https://doi.org/10.21203/rs.3.rs-1070515/v1

License: (9) (7) This work is licensed under a Creative Commons Attribution 4.0 International License. Read Full License

Version of Record: A version of this preprint was published at Microbial Ecology on April 13th, 2022. See the published version at https://doi.org/10.1007/s00248-022-02009-5. 


\section{Abstract}

Nonpoint source pollution (NPSP) from human production and life activities causes severe destruction in river basin environments. In this study, three types of sediment samples (A, NPSP tributary samples; B, non-NPSP mainstream samples; C, NPSP mainstream samples) were collected at the estuary of the NPSP tributary of the Jialing River. High-throughput sequencing of the fungal-specific internal transcribed spacer (ITS) gene region was used to identify fungal taxa. The impact of NPSP on the aquatic environment of the Jialing River was revealed by analysing the community structure, community diversity and functions of sediment fungi. The results showed that the dominant phylum of sediment fungi was Rozellomycota, followed by Ascomycota, Chytridiomycota, Basidiomycota, Mortierellomycota and Zoopagomycota (relative abundance>1\%). NPSP caused a significant increase in the relative abundances of Rozellomycota, Saccharomycetes, Microascales, Saccharomycetales, Branch02 and Branch03. In addition, it caused a significant decrease in the relative abundances of Chytridiomycota, Dothideomycetes, Capnodiales, Glomerellales, Xylariales and Chaetothyriales. Moreover, NPSP caused significant changes in the physicochemical properties of Jialing River sediments, such as $\mathrm{pH}$ and available nitrogen (AN), which significantly increased the species richness of fungi and caused significant changes in the fungal community $\beta$-diversity $(P<0.05)$. $\mathrm{pH}$, total phosphorus (TP) and AN were the main environmental factors affecting fungal communities in Jialing River sediments. The functions of sediment fungi mainly involved three types of nutrient metabolism (symbiotrophic, pathotrophic and saprotrophic) and 75 metabolic circulation pathways. NPSP significantly improved the NONOXIPENT-PWY, PENTOSE-P-PWY, and PWY-6837 metabolic circulation pathway functions $(P<0.05)$ and inhibited the PWY7118, PWY-5920, and PWY-6609 metabolic circulation pathway functions $(P<0.05)$. Hence, NPSP causes changes in the community structure and functions of sediment fungi in Jialing River and destroys the stability of the Jialing River Basin ecosystem.

\section{Introduction}

Rivers are important for the hydrological cycle and for material migration on Earth and have rich biodiversity (Heikkinen et al., 2021). With rapid economic development and the continuous increase in urbanization, China's aquatic environments have been severely damaged, particularly in the form of river pollution, which has become the focus of aquatic environment governance in China (Geng et al., 2019). In recent years, the Chinese government has consistently improved the quality of aquatic environments and strengthened aquatic ecological systems through policy guidance and financial support (Han er al., 2021). However, nonpoint source pollution (NPSP) has not yet been effectively controlled. Research shows that NPSP has surpassed point source pollution as the main cause of water pollution on a global scale, especially in agricultural production in developing countries (Yano et al., 2021; Andrade et al., 2021). Extensive agricultural production, with high input of pesticides and chemical fertilizers, and the rapid expansion of aquaculture has led to increasingly serious agricultural NPSP, and it has severely restricted the healthy development of the aquatic environment (Geng et al., 2019; Arauzo et al., 2021). Therefore, the control of agricultural NPSP has not only become the top priority for water pollution control but also has gradually become a major issue for the sustainable development of modern agriculture and society (Yang et al., 2020).

NPSP is mainly caused by dissolved or solid pollutants in the ground surface or soil, which enter the receiving water through surface runoff, soil erosion, farmland drainage and infiltration (Arauzo et al., 2021; Wu et al., 
2020). NPSP has the characteristics of randomness, extensiveness, lag, and latency, which increases the difficulty of pollution prevention, detection and control (Geng et al., 2019). Therefore, we still need to strengthen the basic scientific research to develop monitoring and control measures that are more accurate and powerful for NPSP control and to reduce the environmental impact on river basins (Costa et al., 2021). Microorganisms can adhere to pollutants entering water bodies and continue to spread to other areas via the water flow (Mushi et al., 2021). Most microorganisms are deposited gradually via attachment to materials such as soil and fallen leaves and reshape the microbial community structure in river sediments under the action of environmental selection, interspecies competition and random diffusion mechanisms (Xu et al., 2021). River sediment is the main site for microbial nutrient metabolism and pollutant degradation. Sediment microorganisms change the aquatic environment conditions through biochemical activities such as assimilation, which further affects the transformation and distribution of nutrients in the sediments and promotes the material cycling of essential elements such as carbon, nitrogen and phosphorus in the sediments (Al-Gabe et al.,2014; Liu et al., 2014; Zhao et al., 2021). When pollutant discharge causes changes in the physical and chemical properties of river sediments, the community structure or functions of sediment microorganisms also change accordingly (Xiang et al., 2021). Therefore, the structural and functional variation in the sediment microbial community is also an important indicator of the stability of river water ecosystems (Bahram et al., 2018). Studying the response of fungal communities in river sediments to NPSP will help improve the level of pollution monitoring. Such research will play a positive role in promoting NPSP control and in aquatic environmental impact assessment.

As an important first-level tributary of the upper reaches of the Yangtze River, the Jialing River is an important ecological barrier for the Yangtze River Basin. A water quality monitoring dataset from the environment management department showed that among the 25 sections of Jialing River tributaries monitored in 2020, the nitrogen and phosphorus levels of 24 did not meet the national level III water quality requirements of China. These areas are dominated by agriculture, with few chemical companies. Almost all of the pollution originates from agricultural NPSP and domestic sewage. At present, the research on NPSP in this area is mainly focused on NPSP output characteristics, pollution load estimation, pollution prevention and control technologies and management (Fang et al., 2021; Kim et al., 2021). However, the study of the effect of NPSP on microbial ecological processes in river sediments has not been reported in detail, especially the mechanism underlying the effect of NPSP on fungal community construction in sediments, which is still unclear (Wu et al., 2020). Therefore, to clarify the characteristics of the sediment fungal community in the Jialing River and reveal the degree of influence of NPSP on the structure and function of the sediment fungal community, we employed the sediment fungi of the Jialing River as the research object using high-throughput sequencing technology and bioinformatic analysis methods to explore the influence of NPSP on the community composition and function of the sediment fungi. Further analysis of the interaction between the diversity of the sediment fungal community and environmental factors is expected to provide a scientific basis for ecological environment protection and NPSP control in the Jialing River Basin.

\section{Materials And Methods}

\section{Study area}

The study area was located in the mid-downstream section (Nanchong Section of Sichuan Province) of the Jialing River $\left(32^{\circ} 10^{\prime}\right.$ to $33^{\circ} 30^{\prime}, 105^{\circ} 50^{\prime}$ to $106^{\circ} 10^{\prime}$ ) (Fig. 1). The Jialing River originates from the Qinling 
Mountains in Shanxi Province. Its main stream flows through Shanxi Province, Gansu Province, Sichuan Province and Chongqing city and flows into the Yangtze River at Chaotianmen, Chongqing City. With a total length of $1345 \mathrm{~km}$, the Jialing River is an important tributary of the Yangtze River, with the largest basin area, second only to the Yalong River in length and second only to the Minjiang River in flow. The average water quality of the Jialing River (Nanchong Section of Sichuan Province) is stable at the national class II standard of water quality, but the water quality of many tributaries of the Jialing River is poor, including rivers with severe NPSP, such as the Xichong River and Dong River, the water quality standards of which fluctuate between classes III and IV all year round, and occasionally class V.

\section{Sample collection}

The study sites were located in the estuary area where the Dong River and Xichong River flow into the Jialing River (Fig. 1). Both tributaries are typical NPSP rivers, with many villages on both sides and no industrial enterprises. In December 2020, the sampling sites of the NPSP tributaries were set up in the Dong River and Xichong River at a distance of $3 \mathrm{~km}$ from their confluence with the Jialing River, the sampling sites of the NPSP main stream were set up at a distance of $5 \mathrm{~km}$ downstream of the main stream from the confluence of the Xichong River and Dong River with the Jialing River, and the sampling sites of the non-NPSP main stream were set up at a distance of $5 \mathrm{~km}$ upstream of the main stream from the confluence of the Xichong River and Dong River with the Jialing River. One river sediment sample was collected at each site, and 1 sample each was collected $100 \mathrm{~m}$ upstream and downstream from the sampling point (Zheng et al., 2021). A total of 18 sediment samples were collected. The NPSP tributary samples collected in the Dong River were named A1-1, A1-2, and A1-3, and the NPSP tributary samples collected in the Xichong River were named A2-1, A2-2, and A2-

3. The non-NPSP mainstream samples collected from the Dong River Estuary were named B1-1, B1-2, and B1-3, and the non-NPSP mainstream samples collected from the Xichong River Estuary were named B2-1, B2-2, and B2-3. The NPSP mainstream samples collected from the Dong River Estuary were named C1-1, C1-2, and C1-3, and the NPSP mainstream samples collected from the Dong River Estuary were C2-1, C2-2, and C2-3.

We used a mud picker to collect sediment samples and pure water to clean the mud picker between sampling sites. The sediment samples were divided into 2 parts. One part weighed approximately $0.05 \mathrm{~kg}$ after removing plants and rocks and was stored in an incubator with dry ice and sent to the laboratory for extraction of sediment fungal DNA. The other sample weighed approximately $1 \mathrm{~kg}$ and was used to determine the physical and chemical properties.

\section{Determination method}

\section{Physicochemical properties of the sediments}

The $\mathrm{pH}$ of the sediment was measured with a pH analyser (HQ30d, HACH, U.S.A.). The sediment total nitrogen (TN) and total carbon (TC) levels were determined using an elemental analyser (VarioEL III, Germany). The sediment total phosphorus (TP) content was measured using alkali fusion-molybdenum antimony spectrophotometry (Genevieve et al. 2019). The sediment total organic carbon (TOC) content was measured using the nondispersive infrared method and an automated TOC analyser (Shimadzu, TOC-VCPH, Japan). The available nitrogen (AN) content was determined using the AN proliferation method. The carbon-to-nitrogen ratio (C/N) was the ratio of total sediment carbon to total nitrogen (Li et al., 2015; Wu et al., 2020). 


\section{Sediment fungal DNA extraction}

Total microbial community DNA was extracted from triplicate sediment samples (each weighing $0.1 \mathrm{~g}$ ) using the E.Z.N.A. ${ }^{\circledR}$ Soil Fungi DNA Kit (Omega Bio-tek, Norcross, GA, U.S.A.) following the manufacturer's instructions (Wang et al., 2014). Then, $1 \%$ agarose gel electrophoresis was used to check the quality of the extracted DNA. The concentration and purity of the DNA were determined by a NanoDrop 2000. Each sample was prepared in triplicate for PCR amplification.

\section{PCR amplification and sequencing}

The fungal internal transcribed spacer (ITS) variable region was amplified by PCR using the primers ITS1F (5'CTTGGTCATTTAGAGGAAGTAA-3') and ITS2R (5'-TCCTCCGCTTATTGATATGC-3') (Chen et al., 2021). The $20 \mu \mathrm{L}$ PCR system contained $4 \mu \mathrm{L}$ of $5 \times$ FastPfu Buffer, $2 \mu \mathrm{L}$ of $2.5 \mathrm{mM}$ dNTPs, $0.8 \mu \mathrm{L}$ of each primer $(5 \mu \mathrm{M}), 0.4 \mu \mathrm{L}$ of TransStart FastPfu DNA Polymerase (TransGenAP221-02), $0.2 \mu \mathrm{L}$ of BSA, and $10 \mathrm{ng}$ of template DNA (Sheik et al. 2012). Amplification was performed in an ABI GeneAmp 9700 thermocycler (ABI, Carlsbad, CA) with the following temperature profile: $95^{\circ} \mathrm{C}$ for $3 \mathrm{~min} ; 33$ cycles of $95^{\circ} \mathrm{C}$ for $30 \mathrm{~s}, 55^{\circ} \mathrm{C}$ for $30 \mathrm{~s}$, and $72^{\circ} \mathrm{C}$ for 45 $\mathrm{s}$; and a final extension at $72^{\circ} \mathrm{C}$ for $10 \mathrm{~min}$. The amplicons of the same sample were mixed and recovered by $2 \%$ agarose gel electrophoresis, and then, the products were purified by the AxyPrep DNA Gel Extraction Kit (Axygen Biosciences, Union City, CA, USA) and detected by $2 \%$ agarose gel electrophoresis. A Quantus ${ }^{\text {TM }}$ Fluorometer (Promega, USA) was used to detect and quantify the recovered products. The NEXTFLEX Rapid DNA-Seq Kit was used to extract PCR products from agarose gels. Sequencing was performed to build the database by using the Illumina MiSeq platform (Fang et al., 2021).

\section{Sequence splicing and annotation}

Original sequencing data were analysed using the qiime2 process (v2020.2). Fastp software (v0.19.6) was used to process the original sequence data, and then, Flash software (v1.2.7) was used to splice the optimized data. The dada2 denoising and analysis process was used to remove duplicates and generate a table with amplicon sequencing variants (ASVs) (Eschen et al., 2020). The RDP classifier Bayesian algorithm was used to perform taxonomic analysis on the ASV sequence with a confidence threshold of 0.7 and compare each sequence with the UNITE database (Unite 8.0/its_Fungi). The results of species classification annotation were obtained.

\section{Statistical analysis}

Several $a$-diversity indexes (Ace, Chao, Shannon and Simpson) were calculated according to the minimum number of sample sequences to describe the richness and diversity of ASVs at the different sites. Venn diagrams were made by using $\mathrm{R}$ language tools. The $\beta$-diversity distance matrix was calculated by principal component analysis (PCA). Based on the results of species annotation, a Circos diagram and community histogram were used to analyse the species composition. Linear discriminant analysis effect size (LEfSe) was used to identify the species characteristics that best explained the differences between two or more groups of samples and the degree of influence of these characteristics on the differences between groups (Huhe et al., 2017). The functions of sediment fungi were predicted and analysed by using the FUNGuild and PICRUSt2 tools according to nutrition mode and metabolic circulation pathway (Schmidt er al., 2018). A redundancy analysis (RDA) was performed in $\mathrm{R}$ using the Vegan package with fungal species abundance and 
environmental chemical data. SPSS software (IBM SPSS Statistics 22 for Windows) was used to calculate Pearson correlation coefficients and to perform one-way ANOVA.

\section{Results}

\section{Differences in the physicochemical properties of sediments at different sites}

The physical and chemical properties of sediments in the Jialing River are affected by many factors, such as water and soil loss in the riparian zone, pollution discharge, and river disturbance. Therefore, the physical and chemical properties of sampling points in different river sections exhibited certain differences. Table S1 shows that the $\mathrm{pH}$ of the sediments at site B was higher than that at the other sites, indicating that NPSP significantly reduced the $\mathrm{pH}$ of the sediments $(P<0.05)$. Compared with that in $\mathrm{B}$, the $\mathrm{AN}$ content in $\mathrm{A}$ and $\mathrm{C}$ was significantly increased $(P<0.05)$. The TC content varied from 5.72 to $15.37 \mathrm{~g} \cdot \mathrm{kg}^{-1}$, the TN content varied from 0.36 to 1.02 $\mathrm{g} \cdot \mathrm{kg}^{-1}$, and the TOC content varied from 4.68 to $12.11 \mathrm{~g} \cdot \mathrm{kg}^{-1}$. These 3 physicochemical parameters showed the same change trends at the different sites. There were certain differences in the TP content and $\mathrm{C} / \mathrm{N}$ value at different sites, but there was no obvious change trend. Hence, the $\mathrm{pH}$ and $\mathrm{AN}$ content of the sediments were significantly affected by NPSP, while the other physicochemical properties of the sediments had no significant relationship with NPSP.

\section{DNA sequencing data and ASV distribution of fungi in sediment samples from different sites}

A total of 1294031 optimized sequences were detected in 18 sediment samples through high-throughput sequencing, with a total base number of 284476801 bp, an average sequence number of 71 891, an average base number of $15804267 \mathrm{bp}$, and an average base length of $219.9 \mathrm{bp}$. The sequences were analysed by ASV taxonomy according to $100 \%$ similarity, and 11184 ASVs were obtained. As shown in Fig. 2, the distribution numbers of ASVs at the 6 sampling sites decreased in the order A1 > C1 > C2 > B1 > A2 > B2, and the numbers of ASVs detected were 4 003, 2 297, 3 922, 2 216, 1 617, and 2 602, respectively.

The numbers of ASVs of the sediment fungal communities from sites $A$ and $C$ of the same estuary were similar (Fig. 2a, 2b). The number of shared ASVs between A and C (1372 shared by A1 and C1 and 773 shared by A2 and C3) is shown in the Venn diagram. A small number of ASVs shared between B and other sites (671 shared by $A 1$ and B1, 624 shared by B1 and C1, 360 shared by A2 and B2, and 352 shared by B2 and C2) are also shown. This shows that the distribution of sediment fungal ASVs in the main stream of the Jialing River is significantly affected by the NPSP tributary and is affected by other environmental factors.

As shown in Fig. 2 (d, e, f), the number of ASVs shared between each pair of sites (749 shared by A1 and A2, 474 shared by B1 and B2, and 825 shared by $C 1$ and C2) and unique to each site (3 254 unique to A1, 1467 to $A 2,1823$ to B1, 1143 to B2, 3097 to $C 1$, and 1777 to C2) are shown in the Venn diagram (Fig. 2d, 2e, 2f). The fungal communities of the two NPSP tributaries exhibited certain differences, and the distribution of fungal ASVs in the sediments of the main stream of the Jialing River showed changes. 


\section{Diversity analysis of the fungal community in sediments from different sites}

\section{a-Diversity analysis of the fungal community in sediments from different sites}

Several a-diversity indexes were calculated to describe the richness and diversity of sediment fungal ASVs at the different sites (Table 1). The independent t-tests used to explore the differences between the six sites indicated that the richness of the sediment fungal community in $\mathrm{C} 1$ was significantly higher than that in other sites $(P<0.05)$. This result indicates that NPSP increased the diversity of fungi in the Jialing River sediments. Similarly, the richness of the sediment fungal community in C2 was significantly higher than that in A2 and B2 $(P<0.05)$. It was further verified that NPSP significantly increased the fungal diversity of sediments $(P<0.05)$.

Table 1

Comparison of the a-diversity index of sediment fungi at different sampling sites. Different lowercase letters denote significant differences between sampling sites at $P<0.05$. The maximum values in each column are denoted by "a". a-Diversity indexes were calculated at the ASV level.

\begin{tabular}{|lllll|}
\hline site & Ace & Chao & Shannon-Wiener & Simpson \\
\hline A1 & $1717.33 \pm 283.83 \mathrm{a}$ & $1717.33 \pm 283.83 \mathrm{a}$ & $6.23 \pm 0.28 \mathrm{ab}$ & $0.0100 \pm 0.0073 \mathrm{~b}$ \\
\hline B1 & $1033.67 \pm 71.23 \mathrm{bc}$ & $1033.67 \pm 71.23 \mathrm{bc}$ & $5.25 \pm 0.13 \mathrm{bc}$ & $0.0218 \pm 0.0075 \mathrm{~b}$ \\
\hline C1 & $1753.33 \pm 77.36 \mathrm{a}$ & $1753.33 \pm 77.36 \mathrm{a}$ & $6.38 \pm 0.08 \mathrm{a}$ & $0.0051 \pm 0.0008 \mathrm{~b}$ \\
\hline A2 & $985.33 \pm 214.76 \mathrm{bc}$ & $985.33 \pm 214.76 \mathrm{bc}$ & $3.93 \pm 1.33 \mathrm{~d}$ & $0.1874 \pm 0.1833 \mathrm{a}$ \\
\hline B2 & $747.33 \pm 66.29 \mathrm{c}$ & $747.33 \pm 66.29 \mathrm{c}$ & $4.50 \pm 0.17 \mathrm{~cd}$ & $0.0431 \pm 0.0015 \mathrm{~b}$ \\
\hline C2 & $1209.00 \pm 46.87 \mathrm{~b}$ & $1209.00 \pm 46.87 \mathrm{~b}$ & $4.44 \pm 0.36 \mathrm{~cd}$ & $0.1029 \pm 0.0240 \mathrm{ab}$ \\
\hline
\end{tabular}

\section{$\beta$-Diversity analysis of the fungal community in sediments from different sites}

The correlations of and differences in the sediment fungal communities among the six sampling sites were compared by PCA of the Pearson distance algorithm at the species level (Fig. 3). The cumulative explained variance of the first axis and the second axis reached $83.64 \%, 92.01 \%$, and $61.97 \%$. The fungal communities at different sampling sites in the same estuary showed no obvious overlap with each other and could be separated from each other. Analysis of similarities (ANOSIM) of the groups showed that the fungal communities in sites $A$ and $C$ of the same estuary shared high similarity and were significantly different from the fungal communities in $\mathrm{B}(P<0.05)$. In addition, Fig. 3c shows that the fungal communities of $\mathrm{B} 2$ and Dong River Estuary sediments shared a certain similarity, and the fungal community diversity of C2 exhibited higher variation, which was affected by NPSP in the Xichong River $(P<0.05)$.

\section{Community structure and indicator species of fungi in sediments from different sites}




\section{Fungal community structure characteristics of sediments from different sites at the phylum level}

Taxonomic analysis of ASVs at the phylum level (Fig. S1) showed that the sediment fungi from all the sites belonged to 14 known phyla. Among them, Rozellomycota, Ascomycota, Chytridiomycota, Basidiomycota, Mortierellomycota and Zoopagomycota were the main fungal phyla at each sampling site (relative abundance> 1\%). Olpidiomucota, Kickxellomycota, Glomeromycota, Blastocladiomycota, Calcarisporiellomycota, Mucoromycota, Basidiobolomycota, and Monoblepharomycota were rare fungal phyla at each sampling site (relative abundance< $1 \%$ ).

\section{Fungal community structure characteristics of sediments from different sites at the genus level}

Taxonomic analysis of ASVs at the genus level (Fig. S2) showed that the sediment fungi from all the sites belonged to 778 genera. Among them, Cladosporium, Paraphaeosphaeria, Saitozyma, Pseudeurotium, Trichoderma, Epicoccum, Penicillium, Plectosphaerella, Didymella, Talaromyces, Tausonia, Botrytis, Acaulopage, and Podospora were known dominant fungal genera at each site. Most of the fungi belonged to rare genera or genera that could not be classified and named.

\section{Analysis of indicator fungi in sediments from different sites}

The LEfSe analysis results show that the characteristics of the fungal communities in the sediments differed among sites (Fig. 4). At the phylum level, Chytridiomycota was the dominant fungal phylum with significant differences in B, while Rozellomycota was the dominant fungal phylum with significant differences in $\mathrm{C}$. At the class level, Dothideomycetes in B and Saccharomycetes in $\mathrm{C}$ were the dominant fungi with significant differences. At the order level, Capnodiales, Glomerellales, Xylariales, and Chaetothyriales in the sediments of B were the dominant fungi with significant differences. Pleosporales, Morosphaeiaceae, Trichosphaeriales, Trichosporonales, and GS11 in the sediments of A were the dominant fungi with significant differences. Microascales, Saccharomycetales, Branch02, and Branch03 in the sediments of $\mathrm{C}$ were the dominant fungi with significant differences. At the family level, Mycosphaerellaceae, Cladosporiaceae, Phaeosphaeriaceae, Periconiaceae, Plectosphaerellaceae, Nectriaceae, Apiosporaceae, Rhynchogastremataceae were the dominant fungal families with significant differences in the sediments of B. Extremaceae, Morosphaeiaceae, Dictyosporiaceae, Hypocreaceae, Trichosphaeriaceae, and Trichosporonaceae were the dominant fungi families with significant differences in the sediments of A. Extremaceae and Inocybaceae were the dominant fungal families with significant differences in the sediments of $\mathrm{C}$. At the genus level, Cercospora, Cladosporium, Dokmaia, Setophaeosphaeria, Paraphoma, Neosetophoma, Periconia, Plectosphaerella, Claviceps, Botrytis, and Papiliotrema were the dominant fungal genera with significant differences in the sediments of B. Acrocalymma, Emericellopsis, Trichoderma, Podospora, Ciboria, and Apiotrichum were the dominant fungal genera with significant differences in the sediments of A. Exosporium, Phialosimplex, Candida, Inocybe, Tausonia, and Slooffia were the dominant genera with significant differences in the sediments of C. At the species level, Setophaeosphaeria badalingensis, Periconia byssoides, Aureobasidium leucospemi, Claviceps sorghicola, Papiliotrema flavescens, and Chytridiomycota sp. were the dominant species with significant differences in the sediments of B. Podospora communis, Talaromyces helices, Basidiomycota sp., and GS11 sp. were the dominant species with significant differences in the sediments of A. Exosporium 
sp., Acaulium sp., Phialosimplex sp., Exophiala oligosperma, Candida sake, Tausonia sp., Slooffia cresolica, and Branch02_sp were the dominant species with significant differences in the sediments of C. In addition, there were some unclassified and unnamed fungi in the sediments of various sites.

\section{Fungal functional groups of sediments in different sites}

The FUNGuild microecological analysis tools were used to predict the utilization of similar environmental resources based on fungal communities. As shown in Fig. S3, the detected sediment fungi were classified into three types (symbiotrophs, pathotrophs, and saprotrophs) according to their absorption and utilization of environmental resources. The fungi were classified into 12 functional groups, including litter saprotrophs, soil saprotrophs, wood saprotrophs, bryophyte parasites, lichen parasites, rhododendron ericoid mycorrhizae, ectomycorrhizae, animal pathogens, dung saprotrophs, plant pathogens, endophytes, and fungal parasites. The 12 functional types were very evenly distributed among various plots, and NPSP did not have a significant impact on the different environmental resource utilization mechanisms.

PICRUSt 2 software was used to predict and analyse the functional metabolic pathways of sediment fungal communities (Table 2). All the samples contained a total of 75 metabolic circulation pathways. Among them, 25 main metabolic circulation pathways showed significant differences among different types of sites (relative abundance of functional gene sequences $>1 \%$ ). The levels of the metabolic circulation pathways PWY-7288, PWY66-409, and PWY-5189 in B were significantly higher than those in the other sites $(P<0.05)$, and the levels of GLYOXYLATE-BYPASS, VALSYN-PWY, PWY-7411, PWY66-422 in B were significantly lower than those in the other sites $(P<0.05)$. The levels of the metabolic circulation pathways GLYOXYLATE-BYPASS, PWY-7210, PWY6317, and PWY-7385 in A were significantly higher than those in the other sites $(P<0.05)$. The levels of PWY7007 and PWY-7208 in A were significantly lower than those in the other sites $(P<0.05)$. The levels of the metabolic circulation pathways NONOXIPENT-PWY, PENTOSE-P-PWY, and PWY-6837 in C were significantly higher than those in the other sites $(P<0.05)$. The levels of PWY-7118, PWY-5920, and PWY-6609 in the $C$ group were significantly lower than those in the other groups $(P<0.05)$. 
Table 2

Comparison of fungal metabolic pathways in the sediments at the sampling sites. Different lowercase letters denote significant differences between sampling sites at $P<0.05$. The maximum values in each column are denoted by "a".

\begin{tabular}{|c|c|c|c|c|}
\hline $\begin{array}{l}\text { metacyc } \\
\text { pathway }\end{array}$ & description & A & B & C \\
\hline PWY-7288 & fatty acid & $0.0337 \pm 0.0037 \mathrm{c}$ & $0.0412 \pm 0.0014 a$ & $0.0337 \pm 0.0016 b$ \\
\hline $\begin{array}{l}\text { GLYOXYLATE- } \\
\text { BYPASS }\end{array}$ & glyoxylate cycle & $0.0272 \pm 0.0014 a$ & $0.0243 \pm 0.0005 c$ & $0.0260 \pm 0.0004 b$ \\
\hline PWY-7184 & $\begin{array}{l}\text { pyrimidine } \\
\text { deoxyribonucleotides de } \\
\text { novo biosynthesis I }\end{array}$ & $0.0214 \pm 0.0003 b$ & $0.0236 \pm 0.0009 a$ & $0.0223 \pm 0.0010 \mathrm{ab}$ \\
\hline PWY-7111 & $\begin{array}{l}\text { pyruvate fermentation to } \\
\text { isobutanol }\end{array}$ & $0.0206 \pm 0.0004 a b$ & $0.0202 \pm 0.0002 b$ & $0.0206 \pm 0.0003 a$ \\
\hline PWY-7228 & $\begin{array}{l}\text { superpathway of } \\
\text { guanosine nucleotides de } \\
\text { novo biosynthesis I }\end{array}$ & $0.0192 \pm 0.0010 \mathrm{~b}$ & $0.0203 \pm 0.0004 a$ & $0.0194 \pm 0.0007 a b$ \\
\hline $\begin{array}{l}\text { NONOXIPENT- } \\
\text { PWY }\end{array}$ & $\begin{array}{l}\text { pentose phosphate } \\
\text { pathway }\end{array}$ & $0.0183 \pm 0.0011 b$ & $0.0182 \pm 0.0004 b$ & $0.0206 \pm 0.0026 a$ \\
\hline PWY-7007 & $\begin{array}{l}\text { methyl ketone } \\
\text { biosynthesis }\end{array}$ & $0.0164 \pm 0.0040 \mathrm{~b}$ & $0.0209 \pm 0.0018 a$ & $0.0196 \pm 0.0003 a$ \\
\hline PWY-7197 & $\begin{array}{l}\text { pyrimidine } \\
\text { deoxyribonucleotide } \\
\text { phosphorylation }\end{array}$ & $0.0183 \pm 0.0013 b$ & $0.0199 \pm 0.0006 a$ & $0.0188 \pm 0.0006 \mathrm{ab}$ \\
\hline PWY-7208 & $\begin{array}{l}\text { superpathway of } \\
\text { pyrimidine nucleobases } \\
\text { salvage }\end{array}$ & $0.0178 \pm 0.0007 \mathrm{~b}$ & $0.0185 \pm 0.0003 a$ & $0.0185 \pm 0.0004 a$ \\
\hline VALSYN-PWY & L-valine biosynthesis & $0.0180 \pm 0.0007 a$ & $0.0177 \pm 0.0002 b$ & $0.0185 \pm 0.0001 a$ \\
\hline PWY-5067 & glycogen biosynthesis II & $0.0174 \pm 0.0011 b$ & $0.0183 \pm 0.0001 a$ & $0.0171 \pm 0.0007 a b$ \\
\hline PANTO-PWY & $\begin{array}{l}\text { phosphopantothenate } \\
\text { biosynthesis I }\end{array}$ & $0.0168 \pm 0.0006 a b$ & $0.0164 \pm 0.0002 b$ & $0.0171 \pm 0.0004 a$ \\
\hline $\begin{array}{l}\text { PENTOSE-P- } \\
\text { PWY }\end{array}$ & $\begin{array}{l}\text { pentose phosphate } \\
\text { pathway }\end{array}$ & $0.0161 \pm 0.0003 b$ & $0.0161 \pm 0.0002 b$ & $0.0168 \pm 0.0008 a$ \\
\hline PWY-7118 & $\begin{array}{l}\text { chitin degradation to } \\
\text { ethanol }\end{array}$ & $0.0169 \pm 0.0021 a$ & $0.0171 \pm 0.0011 a$ & $0.0139 \pm 0.0004 b$ \\
\hline PWY-7411 & $\begin{array}{l}\text { superpathway of } \\
\text { phosphatidate } \\
\text { biosynthesis }\end{array}$ & $0.0159 \pm 0.0005 a$ & $0.0151 \pm 0.0004 b$ & $0.0161 \pm 0.0006 a$ \\
\hline PWY-6837 & $\begin{array}{l}\text { fatty acid beta-oxidation } \\
\checkmark\end{array}$ & $0.0131 \pm 0.0025 b$ & $0.0150 \pm 0.0009 b$ & $0.0175 \pm 0.0021 a$ \\
\hline PWY-7282 & $\begin{array}{l}\text { 4-amino-2-methyl-5- } \\
\text { phosphomethylpyrimidine } \\
\text { biosynthesis }\end{array}$ & $0.0157 \pm 0.0008 a$ & $0.0150 \pm 0.0006 \mathrm{ab}$ & $0.0147 \pm 0.0001 b$ \\
\hline
\end{tabular}




\begin{tabular}{|c|c|c|c|c|}
\hline $\begin{array}{l}\text { metacyc } \\
\text { pathway }\end{array}$ & description & A & B & C \\
\hline PWY66-422 & D-galactose degradation & $0.0151 \pm 0.0004 a$ & $0.0145 \pm 0.0004 b$ & $0.0151 \pm 0.0003 a$ \\
\hline PWY-7210 & $\begin{array}{l}\text { pyrimidine } \\
\text { deoxyribonucleotides } \\
\text { biosynthesis from CTP }\end{array}$ & $0.0156 \pm 0.0018 a$ & $0.0138 \pm 0.0011 b$ & $0.0137 \pm 0.0012 b$ \\
\hline PWY-5920 & $\begin{array}{l}\text { superpathway of heme } \\
\text { biosynthesis from glycine }\end{array}$ & $0.0134 \pm 0.0007 a$ & $0.0120 \pm 0.0009 a$ & $0.0128 \pm 0.0002 b$ \\
\hline PWY66-409 & $\begin{array}{l}\text { superpathway of purine } \\
\text { nucleotide salvage }\end{array}$ & $0.0115 \pm 0.0020 \mathrm{~b}$ & $0.0140 \pm 0.0009 a$ & $0.0119 \pm 0.0010 \mathrm{~b}$ \\
\hline PWY-5189 & $\begin{array}{l}\text { tetrapyrrole biosynthesis } \\
\text { II }\end{array}$ & $0.0125 \pm 0.0010 \mathrm{~b}$ & $0.0103 \pm 0.0011 a$ & $0.0117 \pm 0.0001 b$ \\
\hline PWY-6609 & $\begin{array}{l}\text { adenine and adenosine } \\
\text { salvage III }\end{array}$ & $0.0120 \pm 0.0016 a$ & $0.0123 \pm 0.0004 a$ & $0.0097 \pm 0.0015 b$ \\
\hline PWY-6317 & galactose degradation I & $0.0122 \pm 0.0016 a$ & $0.0100 \pm 0.0007 b$ & $0.0104 \pm 0.0015 b$ \\
\hline PWY-7385 & $\begin{array}{l}\text { 1,3-propanediol } \\
\text { biosynthesis }\end{array}$ & $0.0119 \pm 0.0013 a$ & $0.0099 \pm 0.0009 \mathrm{~b}$ & $0.0104 \pm 0.0008 b$ \\
\hline
\end{tabular}

The correlation analysis between the sediment physicochemical properties and sediment fungal $\alpha$-diversity showed (Table S2) that the Ace index and Chao index were significantly negatively correlated with sediment $\mathrm{pH}$ $(P<0.05)$ and significantly positively correlated with the sediment TN and AN levels $(P<0.05)$. This indicates that the $\mathrm{pH}, \mathrm{TN}$ and $\mathrm{AN}$ levels have significant effects on the fungal species richness of sediments.

Redundant analysis of sediment fungal community structure and sediment physical and chemical properties at the species level (Fig. 5). The results show that the cumulative explained variation of the two axes reached $75.95 \%$, reflecting more than $70 \%$ of the sediment fungal community change characteristics and influencing factors. The results of the displacement test showed that the sediment $\mathrm{pH}\left(r^{2}=0.6189, P=0.002\right)$, TP content $\left(r^{2}=0.4486, P=0.016\right)$ and AN content $\left(r^{2}=0.3321, P=0.049\right)$ were the key environmental factors that led to structural variation in the fungal communities.

\section{Discussion}

\section{Effects of NPSP on fungal communities in sediments of the Jialing River}

NPSP is caused mainly by pesticides and fertilizers used in agricultural production and the discharge of rural domestic sewage. This type of pollution is associated with a large number of organic pollutant particles and terrestrial environmental microorganisms, which have a great impact on the microbial diversity of water sediments (Wu et al., 2020; Liu et al., 2020; Sun et al., 2020). To date, few studies have examined the impact of 
human activities on river microbial community diversity and the underlying diffusion mechanism. Some related studies have shown that environmental microbial diversity is closely related to human production and life activities, and human activities have changed the environment and the associated microbial community diversity (Wang et al., 2019). Han er al. (2021) found that human pollution discharge can lead to a significant increase in the diversity of planktonic fungal communities in the main stream of the Laohe River, which is basically consistent with the results of this study. This study shows that the two tributaries in the study area both flow through a large area, including both urban and rural areas, and receive urban sewage discharge, fertilizers and pesticides, leading to NPSP being the most important form of pollution for the two tributaries. The diversity of fungal communities in the sediments of the Jialing River after the two tributaries merged into the main stream was significantly higher than that before merging, and the changes in the fungal diversity of the sediments in the main stream tended to be consistent. This phenomenon could be attributed mainly to microbial attachment to the particulate pollutants of the land environment and gradual deposition of these microbes in the estuary. Changes in the diversity of the microbial communities in sediments occurred through environmental selection, interspecies competition and random diffusion mechanisms (Xu et al., 2018; Jiao et al., 2020). At the same time, NPSP caused an increase in nutrients in the river water, and gradual deposition in the estuary improved the nutrient conditions and oxygen flux in the sediments, which significantly increased the diversity of the fungal community in the sediments (Foster et al., 2021). The RDA results for A1 and C1 showed partial overlap, as did those for A2 and C2. This indicated that the influx of NPSP tributaries had a significant impact on the fungal community in the main stream of the Jialing River. At the same time, the fungal community showed partial overlapped between B1 and B2. The upstream riparian zones of B1 and B2 have a good ecological environment, having a significant maintenance and protection effect on the diversity of the fungal community. The physical and chemical properties of sediments are the main factors affecting the diversity of fungal communities in sediments. Generally, nutrients such as carbon, nitrogen and phosphorus affect the growth and metabolism of microorganisms. Studies have shown that organic carbon is the main environmental factor affecting the fungal community in the sediments of the Poyang Lake Estuary, while the abundance and diversity of the fungal community have no significant correlation with environmental factors such as sediment $\mathrm{pH}$, organic carbon, organic nitrogen, and $\mathrm{C} / \mathrm{N}$ (Li et al., 2020). This study showed that $\mathrm{pH}$, TP and AN are the main environmental factors affecting fungal communities in Jialing River sediments. The difference in research results may be related to differences between the research areas. The sites studied by Wang Peng and others were set in the same area, and the $\mathrm{pH}$ value was relatively stable. However, the $\mathrm{pH}$ of the sites in this study fluctuated greatly under the disturbance caused by NPSP, which affected the community diversity of sediment fungi. In addition, nutrients such as carbon, nitrogen, and phosphorus usually function in accordance with the "barrel principle", indicating that the lack of nutrients in the area may be the first limiting factor affecting the diversity of the microbial community (Abia et al., 2018).

NPSP leads to increased nutrient flux in river water bodies, destroys the aquatic ecosystem, and changes the fungal community composition (Wu et al., 2020). In our previous studies, the dominant fungi in wetlands along the Songhua River were Ascomycota, Basidiomycota, Mortierellomycota and Rozellomycota (Xu et al., 2021). Song et al. (2020) found that the dominant fungi in the fungal community in small water bodies were Ascomycota and Basidiomycota. This study showed that the dominant fungi in the Jialing River sediments disturbed by NPSP belonged to Rozellomycota, while the dominant fungi in the non-NPSP sites belonged to Ascomycota. Ascomycota and Basidiomycota are the dominant phyla in most natural environments. However, 
the composition of fungi in different research environments has certain specificities, and Rozellomycota may be more closely related to human activities (baudy et al., 2021).

\section{Effect of NPSP on the fungal function of sediments in the Jialing River}

To date, most studies on fungal functions have focused on the type of resource utilization and have classified fungi as symbiotrophs, pathotrophs, or saprotrophs (Zhou et al. 2021). Few studies have carried out detailed analysis of the fungal metabolic pathways, especially in research on the impact of NPSP on sediment fungal function, which is completely insufficient. Studies by Zheng et al. (2021) have shown that the planktonic fungi in the Danjiangkou Reservoir area are mainly pathotrophic, saprotrophic and pathotrophic-saprotrophic. Among them, the proportion of plant pathogens and animal pathogens is relatively high, and there are potential ecological risks. This is very similar to our research results. In this study, the ITS genome of the fungi in the sediments of the Jialing River was sequenced, and FUNGuild function prediction analysis was performed. The results showed that the functions of sediment fungi are mainly saprotrophic and include two types of nutrient metabolism: symbiotrophic and pathotrophic. The fungi with the three types of nutrient metabolism can be divided into 12 functional types: litter saprotrophs, soil saprotrophs, wood saprotrophs, bryophytic parasites, lichen parasites, ericoid mycorrhizal fungi, ectomycorrhizal fungi, animal pathogenic fungi, dung saprotrophs, plant pathogens, endophytes and fungal parasites. Many fungal groups have one or more of the above nutrient metabolism functions. At the same time, we did not find that NPSP had a significant impact on certain nutrient metabolism functions. This also showed that although the environment has undergone major changes, the nutrient metabolism function of fungi has remained relatively intact, and fungi can play an important role in maintaining the structure and function of the ecosystem (Li et al., 2019).

We used the PICRUSt2 tool to further analyse the metabolic pathways of sediment fungi in the Jialing River. The results showed that the fungi in the sediments of the Jialing River had 75 metabolic circulation pathways.

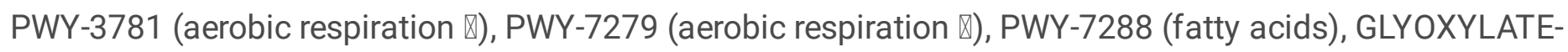
BYPASS (glyoxylate cycle), PWY-7219 (de novo biosynthesis of adenosine ribonucleotide), PWY-5690 (TCA cycle II), PWY-6351 (D-myo-inositol), etc., were the most important metabolic circulation pathways of sediment fungi. NPSP directly or indirectly affected 25 of the metabolic circulation pathways. NPSP significantly improved the functions of the NONOXIPENT-PWY, PENTOSE-P-PWY, and PWY-6837 metabolic circulation pathways $(P<0.05)$ and inhibited the functions of metabolic circulation pathways such as PWY-7118, PWY5920 , and PWY-6609 $(P<0.05)$. The effects of NPSP on these metabolic circulation pathways are highly complex. It is very likely that human production and life activities cause antibiotics and pharmaceuticals to enter water bodies with NPSP, which has a toxic effect on certain fungal communities and inhibits the corresponding fungal metabolic circulation pathways (Liu et al., 2021). It is also possible that after a pollutant enters the water body, its toxicity is weakened or it is converted into easily degraded compounds (Lin et al. 2019). The microorganisms in the sediments transform or decompose exogenous biological substances, leading to increased performance in exogenous substance biodegradation and metabolic functions (Chen et al., 2019; Purahong et al., 2016). At present, the relevant research is very limited, and the database itself has certain limitations. It is recommended that additional study directions should be considered and may be combined with metagenomic sequencing methods to perform an in-depth study of fungal functions in the sediment environment. 


\section{Ecological measures and management suggestions for NPSP}

NPSP has become a key issue restricting the sustainable development of China's rural areas. The main contradiction lies in the relationship between rural economic development and aquatic environmental protection (Yang et al., 2020). The results of the present study clearly showed that NPSP caused changes in the structure and function of fungal communities in river sediments and posed a potential threat to the ecological environment (Liu et al., 2020). Hence, it is urgent to strengthen research on rapid identification, monitoring and evaluation and comprehensive treatment technologies (Chen et al. 2016). Studies have shown that the treatment of NPSP is divided into three parts: reduction at the source, runoff control, and end treatment (Wang et al., 2019). Ecological treatment methods are the cheapest and most effective measure to control NPSP. Therefore, to reduce NPSP and promote the health and stability of the ecological environment, it is recommended to speed up the development of ecological agriculture production methods based on transformation and comprehensive utilization of rural domestic sewage and waste resources, the optimization of agricultural planting layouts and fertilization structures, and the implementation of ecological farming. In addition, based on the results of this study, the identification of NPSP environmental microbial indicators should be further studied. The monitoring and evaluation of environmental microbial indicator species at the source of pollution should be developed to scientifically manage NPSP discharge (Geng et al., 2019). Ecological measures for NPSP prevention and control involve interconnected production, life and ecological functions. The function of ecological control measures is closely related to the rationality of optimizing land use types (Jiao et al., 2020). In terms of NPSP runoff control, the construction mode and location of the waterway intersection zone, ecological ditches, and vegetation buffer zone should be optimized to give full play to the filtering function. In terms of terminal treatment, large wetland habitat areas should be constructed to exert degradation, adsorption and metabolism functions and to ensure that NPSP is effectively controlled before entering natural rivers (Zhang et al., 2015). Finally, identifying the structure and characteristics of various pollution sources and formulating comprehensive control strategies are the key to comprehensive pollution-based NPSP control (Wu et al., 2020). It is recommended to summarize the land use types, land use characteristics, and multi-functional composition of various ecological measures in combination with cases and documents. The classification of the different functions of ecological measures at different scales provides a theoretical basis for the optimal design of NPSP ecological measures.

\section{Conclusions}

In this study, we obtained novel insights into the impact of NPSP on the diversity and function of fungal communities in river sediments. The results showed that the dominant phylum of sediment fungi was Rozellomycota, followed by Ascomycota, Chytridiomycota, Basidiomycota, Mortierellomycota and Zoopagomycota (relative abundance>1\%). NPSP had a significant promoting effect on Rozellomycota, Saccharomycetes, Microascales, Saccharomycetales, Branch02, Branch03, etc., and a significant inhibitory effect on Chytridiomycota, Dothideomycetes, Capnodiales, Glomerellales, Xylariales, Chaetothyriales, etc. $(P<0.05)$. NPSP caused significant changes in the physicochemical indicators of Jialing River sediments, such as $\mathrm{pH}$ and $\mathrm{AN}$, changes in which significantly increased the abundance of fungal species and caused significant changes in the fungal community $\beta$-diversity. $\mathrm{pH}, \mathrm{TP}$ and $\mathrm{AN}$ are the main environmental factors affecting bacterial communities in Jialing River sediments. The functions of sediment fungi mainly involve 3 
types of nutrient metabolism (symbiotrophic, pathotrophic and saprotrophic) and 75 metabolic circulation pathways. NPSP significantly improved the NONOXIPENT-PWY, PENTOSE-P-PWY, and PWY-6837 metabolic circulation pathway functions $(P<0.05)$ and inhibited the PWY-7118, PWY-5920, and PWY-6609 metabolic circulation pathway functions $(P<0.05)$. The structure and function of the fungal community in the sediments of the Jialing River changed under the combined effect of NPSP and the physicochemical conditions of the sediments. A good aquatic environment has an important role in stabilizing, maintaining and protecting the fungal community in sediments.

\section{Declarations}

Acknowledgements We thank for the American Journal Expert agent (AJE) to help with the manuscript revision

Funding This study was financially supported by the Science Research Program of China West Normal University (Project No. 19E061), the Environmental Protection Research Program of the Yangtze River (Project No. CJZDZYJ47) and the National Science Foundation of China (NSFC) (Project No. 41907132).

Author contributions Fei Xu: Writing - original draft preparation; Lanping Zhu: Reviewing, Checking and Editing; Yuqin Xue: Investigation; Kunhe Liu: Software, Data curation; Fubin Zhang: Software, Data curation; Tuo Zhang: Conceptualization, Supervision, Funding acquisition.

Data Availability The data involved in this article have been included in the results section and the supplementary information.

Code Availability Not applicable.

\section{Deceleration}

Competing Interests The authors declare no competing interests

Ethics Approval Not applicable

\section{References}

1. Abia A.L.K., Alisoltani A., Keshri J., Ubomba-Jaswa E., 2018. Metagenomic analysis of the bacterial communities and their functional profiles in water and sediments of the Apies River, South Africa, as a function of land use. Sci. Total Environ. 616-617, 326-

334. https://doi.org/10.1016/j.scitotenv.2017.10.322.

2. Al-Gabr H.M., Zheng T.L., Yu X., 2014. Occurrence and quantification of fungi and detection of mycotoxigenic fungi in drinking water in Xiamen City, China. Sci. Total Environ. 466, 11031111. https://doi.org/10.1016/j.scitotenv.2012.12.060.

3. Andrade V.S., Gutierrez M.F., Regaldo L., Paira A.R., Repetti M.R., Gagneten A.M., 2021. Influence of rainfall and seasonal crop practices on nutrient and pesticide runoff from soybean dominated agricultural areas in Pampean streams, Argentina. Sci. Total Environ. 788, 147676-

147676. https://doi.org/10.1016/j.scitotenv.2021.147676. 
4. Arauzo M., Valladolid M., García G., Andries D.M., 2022. N and P behaviour in alluvial aquifers and in the soil solution of their catchment areas: How land use and the physical environment contribute to diffuse pollution. Sci. Total Environ. 804. https://doi.org/10.1016/J.SCITOTENV.2021.150056.

5. Bahram M., Hildebrand F., Forslund S.K., Anderson J.L., Soudzilovskaia N.A., Bodegom P.M., BengtssonPalme J, Anslan J, Coelho L.P., Harend H., Huerta-Cepas J., Medema M.H., Maltz M.R., Mundra S., Olsson P.A., Pent M., Põlme S., Sunagawa S., Ryberg M., Tedersoo L., Bork P., 2018. Structure and function of the global topsoil microbiome. Nature 560: 233-237. https://doi.org/10.1038/s41586-018-0386-6.

6. Baudy P., Zubrod J.P., Konschak M., Kolbenschlag S., Pollitt A., Baschien C., Schulz R., Bundschuh M., 2021. Fungal-fungal and fungal-bacterial interactions in aquatic decomposer communities: bacteria promote fungal diversity. Ecology 102(10), e03471. https://doi.org/ 10.1002/ecy.3471.

7. Chen K.H., Longley R., Bonito, G., Liao, H.L., 2021. A two-step PCR protocol enabling flexible primer choice and high sequencing yield for Illumina MiSeq meta-barcoding. Agronomy-basel 11(7):

1274. https://doi.org/10.3390/agronomy11071274.

8. Chen J., Heikkinen J., Hobbie E.A., Rinne-Garmston K.T., Penttilä R., Mäkipää R., 2019. Strategies of carbon and nitrogen acquisition by saprotrophic and ectomycorrhizal fungi in Finnish boreal Picea abiesdominated forests. Fungal Biol. 123(6), 456-464. https://doi.org/10.1016/j.funbio.2019.03.005.

9. Chen L., Wang G.B., Zhong Y.C. Shen Z.Y., 2016, Evaluating the impacts of soil data on hydrological and nonpoint source pollution prediction. Sci. Total Environ. 563, 19-

28. https://doi.org/10.1016/j.scitotenv.2016.04.107.

10. Costa M.E.L., Carvalho D.J., Koide S., 2021. Assessment of pollutants from diffuse pollution through the correlation between rainfall and runoff characteristics using EMC and first flush analysis. Water 13(18), 2552-2552. https://doi.org/10.3390/w13182552.

11. Eschen R., Allan E., Hartmann M., Schneider S., Prospero S, 2020. Drivers of richness and community composition of fungal endophytes of tree seeds. FEMS Microbiolo. Ecol. 96(9), 166-

175. https://doi.org/10.1093/femsec/fiaa166.

12. Fang T., Li Y.C., Yao Z.X., Li Y.F., Wang X.M., Wang Y., Yu Y.F., 2021. Effects of planting broadleaf trees and Moso bamboo on soil carbon mineralization and microbial community structure. China. J. Appl. Ecol. 32(01), 82-92. https://doi.org/10.13287/j.1001-9332.202101.033.

13. Fang Z.D., Su J.J., Zhao H.T., Hu L., Li X.Y., 2021. Output characteristics of nitrogen and phosphorus from nonpoint source pollution of typical land use in a micro-watershed in Hilly red soil region. Environ. Sci. 42(9). https://doi.org/10.13227/j.hjkx.202103163.

14. Foster S., Chilton J., 2021. Policy experience with groundwater protection from diffuse pollution-A review. Curr. Opin. Environ. Sci. Heal. 23, 100288. https://doi.org/10.1016/j.coesh.2021.100288.

15. Genevieve L., Pierre-Luc C., Roxanne G.T., Amelie M., Danny B., Vincent M., Hugo G., 2019. Estimation of fungal diversity and identification of major abiotic drivers influencing fungal richness and communities in Northern Temperate and Boreal Quebec Forests. Forests 10(12), 1096. https://doi.org/10.3390/f10121096.

16. Geng R.Z. Liang X.J., Yin P.H., Wang M., Zhou L.L., 2019. A review: multi-objective collaborative optimization of best management practices for non-point sources pollution control. Acta Ecol. Sinica. 39(8), 2667-2675. https://doi.org/10.5846/stxb201804140860. 
17. Han X.M., Gong Z.L., Yang X.M., Li Y.Y., Chen Z.J., Zhu H.H., Wang F.M., 2021. Community diversity and function prediction of bacterioplankton in the main stream of Laoguan River before and after flood season. Environ. Sci. 42(02):831-841. https://doi.org/10.13227/j.hjkx.202007082.

18. Heikkinen K., Saari M., Heino J., Ronkanen A.K., Kortelainen P., Joensuu S., Vilmi A., Karjalainen S.M., Hellsten S.; Visuri M., Marttila H., 2021. Iron in boreal river catchments: Biogeochemical, ecological and management implications. Sci. Total Environ. 805. https://doi.org/10.1016/J.SCITOTENV.2021.150256.

19. Huhe, Chen X., Hou F., Wu Y.P., Cheng Y.X., 2017. Bacterial and fungal community structures in loess plateau grasslands with different grazing intensities. Front. Microbiolo. 8:

606. https://doi.org/10.3389/fmicb.2017.00606.

20. Jiao S., Yang Y.F., Xu Y.Q., Zhang J., Lu Y.H., 2020. Balance between community assembly processes mediates species coexistence in agricultural soil microbiomes across eastern China. ISME J. 14(1), 202-216. https://doi.org/10.1038/s41396-019-0522-9.

21. Kim J., Park B., Choi J., Park M., Lee J.M., Kim K., Kim Y., 2021. Optimum detailed standards to control nonpoint source pollution priority panagement areas: centered on highland agriculture watershed. Sustainability 13(17), 9842-9842. https://doi.org/10.3390/SU13179842.

22. Li C.C., Quan Q., Gan Y.D., Dong J.Y., Fang J.H., Wang L.F., Liu J., 2020. Effects of heavy metals on microbial communities in sediments and establishment of bioindicators based on microbial taxa and function for environmental monitoring and management. Sci. Total Environ. 749, 141555. https://doi.org/10.1016/j.scitotenv.2020.141555.

23. Li Q.X., Feng J., Wu J.J., Jia W., Zhang Q., Chen Q., Zhang D.D., Cheng X.L., 2019. Spatial variation in soil microbial community structure and its relation to plant distribution and local environments following afforestation in central China. Soil Till. Res. 193, 8-16. https://doi.org/10.1016/j.still.2019.05.015.

24. Li Y.J., Wang H., Zhao J.N., Huang P.C.H., Yang D.L., 2015. Effects of tillage methods on soil physicochemical properties and biological characteristics in farmland: A review. Chinese J. Appl. Ecol. 26(3), 939-948. https://doi.org/10.13287/j.1001-9332.20150106.018.

25. Lin Y.B., Ye Y.M., Hu Y.M., Shi H.K., 2019. The variation in microbial community structure under different heavy metal contamination levels in paddy soils. Ecotox. environ. Safe. 180, 557-564. https://doi.org/10.1016/j.ecoenv.2019.05.057.

26. Liu J.L., Le T.H., Zhu H.N., Yao Y.A., Zhu H.L., Cao Y., Zhao Z., 2020. Afforestation of cropland fundamentally alters the soil fungal community. Plant Soil 457(1-2), 279-292. https://doi.org/10.1007/s11104-020-04739-2.

27. Liu X.M., Wang D., Wang L., Tang J.C., 2021. Dissolved biochar eliminates the effect of Cu (II) on the transfer of antibiotic resistance genes between bacteria. J. Hazard. Mater. 424. https://doi.org/10.1016/J.JHAZMAT.2021.127251.

28. Liu Y., Zhang J.X., Zhang X.L., Xie S.G., 2014. Depth-related changes of sediment ammonia-oxidizing microorganisms in a high-altitude freshwater wetland. Appl. Microbiol. Biot. 98(12): 56975707. https://doi.org/10.1007/s00253-014-5651-5.

29. Purahong W., Kruger D., Buscot F., Wubet T., 2016. Correlations between the composition of modular fungal communities and litter decomposition-associated ecosystem functions. Fungal Ecol. 22, 106114. https://doi.org/ 10.1016/j.funeco.2016.04.009. 
30. Schmidt R., Mitchell J., Scow K., 2019. Cover cropping and no-till increase diversity and symbiotroph: saprotroph ratios of soil fungal communities. Soil Biol. Biochem. 129: 99-

109. https://doi.org/10.1016/j.soilbio.2018.11.010.

31. Song F.M., Guo D.D., Chen Y.G., Yang Q.L., Wang W.M., 2020. Influence of industrial organic pollution on fungal community in the sediment of small water body. Microbiol. China 47(10), 3216-3225. https://doi.org/10.13344/j.microbiol.china.200170.

32. Sun S.Y., Zhang J.F., Cai C.J., Cai Z.Y., Li X.G., Wang R.J., 2020. Coupling of non-point source pollution and soil characteristics covered by Phyllostachys edulis stands in hilly water source area. J. Environ. Manage. 268, 110657. https://doi.org/10.1016/j.jenvman.2020.110657.

33. Mushi D., Kebede G., Linke R.B., Lakew A., Hayes D.S., Graf W., Farnleitner A.H., 2021. Microbial faecal pollution of river water in a watershed of tropical Ethiopian highlands is driven by diffuse pollution sources. J. Water Health 19(4), 575-591. https://doi.org/10.2166/wh.2021.269.

34. Wang H.L., He P., Shen C.Y., Wu Z.N., 2019. Effect of irrigation amount and fertilization on agriculture nonpoint source pollution in the paddy field. Environ. Sci. Pollut. R. 26(10), 10363-10373. https://doi.org/ 10.1007/s11356-019-04375-z.

35. Wang M., Shi S., Lin F., Jiang P., 2014. Response of the soil fungal community to multi-factor environmental changes in a temperate forest. Appl. Soil Ecol. 81:45-

56. https://doi.org/10.1016/j.apsoil.2014.04.008.

36. Wang R., Xu S.J., Jiang C.C., Zhang Y., Bai N., Zhuang G.Q., Bai Z.H., Zhuang X.L., 2019. Impacts of human activities on the composition and abundance of sulfate-reducing and sulfur-oxidizing microorganisms in polluted river sediments. Front. Microbio. 231(10): https://doi.org/10.3389/fmicb.2019.00231.

37. Wu L., Misselbrook T.H., Feng L.P., Wu L.H., 2020. Assessment of nitrogen uptake and biological nitrogen fixation responses of soybean to nitrogen fertiliser with SPACSYS. Sustainability, 12(15): 5921. https://doi.org/10.3390/su12155921.

38. Wu Y.H., Rene E.R., Zhou M.H., Tiwari A., 2020. Non-point source pollution control and aquatic ecosystem protection-An introduction. Bioresource Technol. 316, 123956. https://doi.org/10.1016/j.biortech.2020.123956.

39. Xiang S.Z., Li Y.Q., Wang W.Y., Zhang B., Shi W.Y., Zhang J., Huang F.Y., Liu F., Guan X.Y., 2021. Antibiotics adaptation costs alter carbon sequestration strategies of microorganisms in karst river. Environ. Pollut. 288:117819. https://doi.org/10.1016/j.envpol.2021.117819.

40. Xu F., Zhang T., Huai B.D., Sui W.Z., Yang X., 2021. Effects of land use changes on soil fungal community structure and function in the riparian wetland along the downstream of Songhua River. Environ. Sci. 42(5), 2531-2540. https://doi.org/10.13227/J.HJKX.202008307.

41. Xu Z., Woodhouse J.N., Te S.H., Gin K.Y.H., He Y.L., Xu C., Chen L., 2018. Seasonal variation in the bacterial community composition of a large estuarine reservoir and response to cyanobacterial proliferation. Chemosphere 202, 576-585. https://doi.org/10.1016/j.chemosphere.2018.03.037.

42. Yang M.Y., Pan X.Y., Liu H.L., Yu L., Chen H., Wang J.W., 2020. Urban non-point pollution characteristics in China: a meta-analysis. Ecol. Environ. Sci. 29(08), 1634-1644. https://doi.org/10.16258/j.cnki.16745906.2020.08.015. 
43. Yano K.A., Geronimo F.K., Reyes N.J., Kim L.H., 2021. Characterization and comparison of microplastic occurrence in point and non-point pollution sources. Sci. Total Environ. 797(25),

148939. https://doi.org/10.1016/j.scitotenv.2021.148939.

44. Zhang T., Ni J.P., Xie D.T., 2015. Severe situation of rural nonpoint source pollution and efficient utilization of agricultural wastes in the Three Gorges Reservoir Area. Environ. Sci. Pollut. R. 22(21), 16453-

16462. https://doi.org/10.1007/s11356-015-5429-z.

45. Zheng B.H., Wang X.Y., Li Y.J., Chen Y, Li B.L., Li Y.Y., Chen Z.J., 2021. Community structure, function, and influencing factors of planktonic fungi in the Danjiangkou reservoir. Environ. Sci. 42(1), 234-

241. https://doi.org/10.13227/j.hjkx.202006192.

46. Zhao C.S., Pan X., Yang S.T., Xiang H., Zhao J., Gan X.J., Ding S.Y., Yu Q., 2021. Effects and prediction of nonpoint source pollution on the structure of aquatic food webs. Ecohydrology 14(1), e2257. https://doi.org/ 10.1002/eco.2257.

47. Zhou J.B., Jin Z.J., Xiao Y.Y.,Leng M., Wang X.T., Pan F.J., 2021. Investigation of soil fungal communities and functionalities within karst paddy field. Environ. Sci. 42(08), 4005-4014.

https://doi.org/10.13227/j.hjkx.202011164.

\section{Figures}

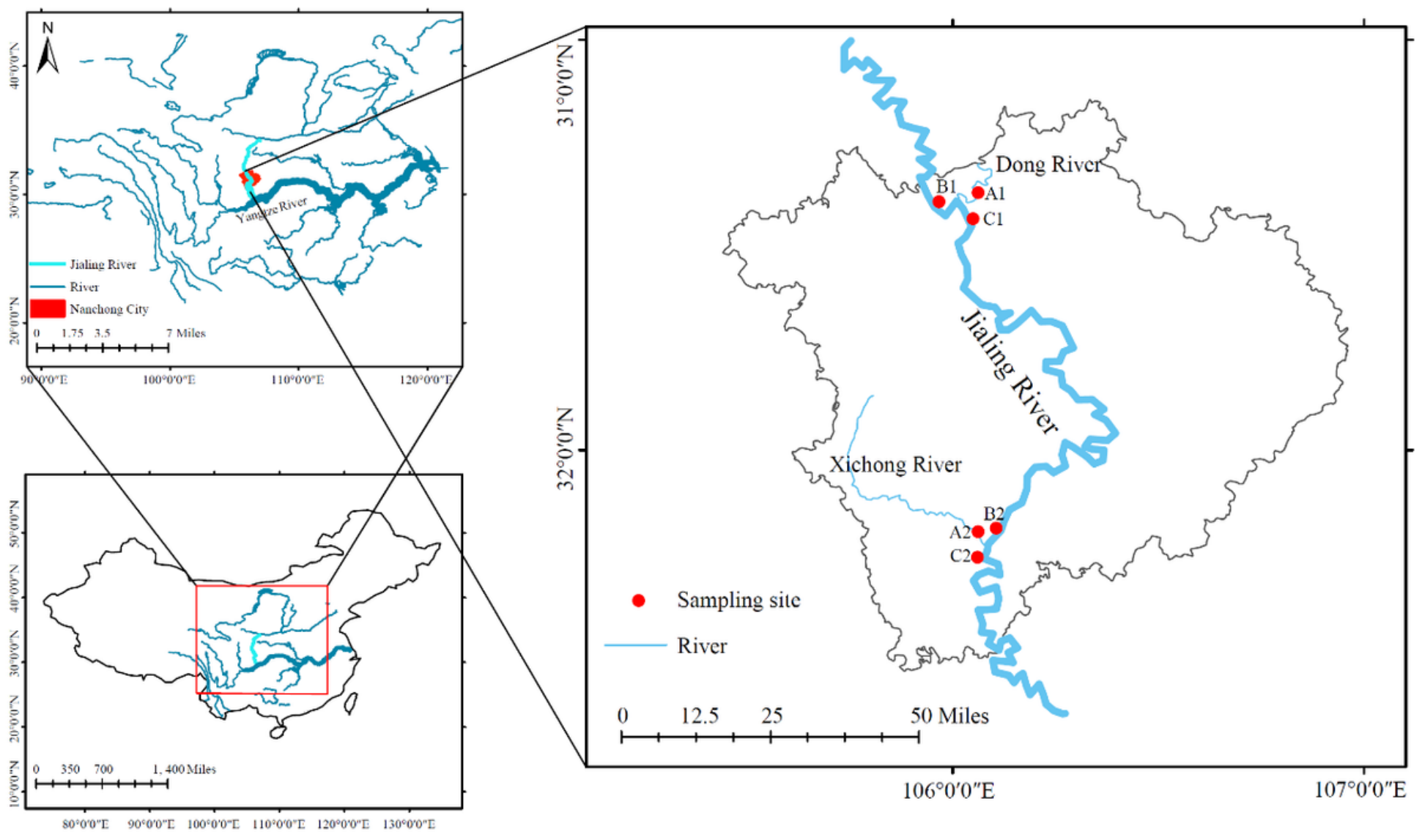

Figure 1

Map of study areas and location of six sampling sites. 


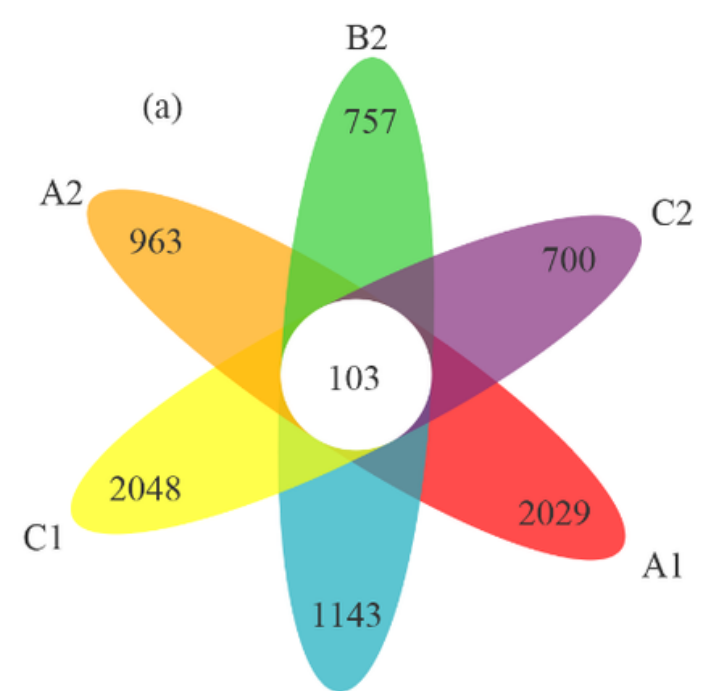

B1

(d)

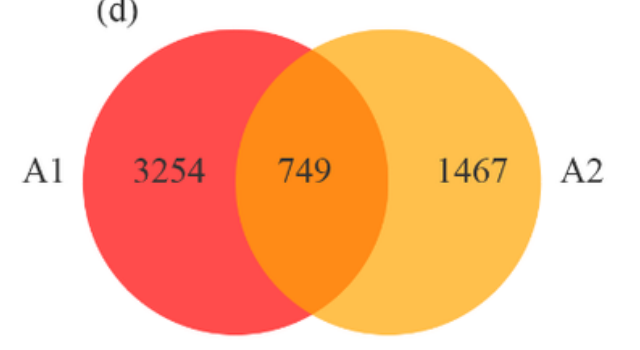

(b)

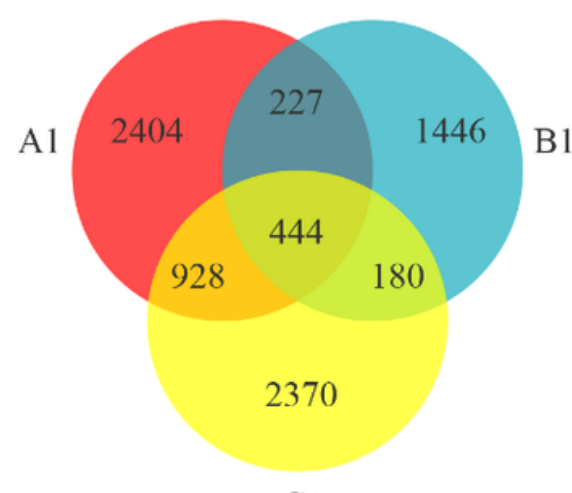

C1

(c)

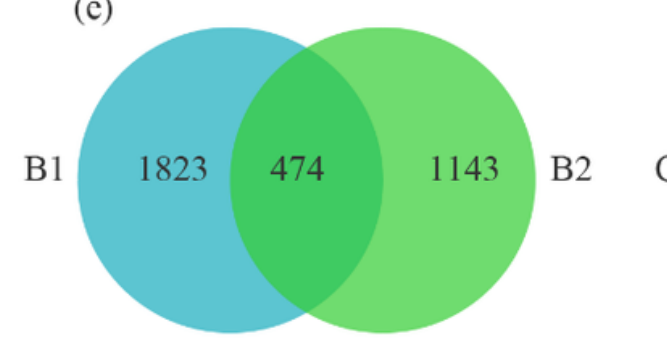

(c)

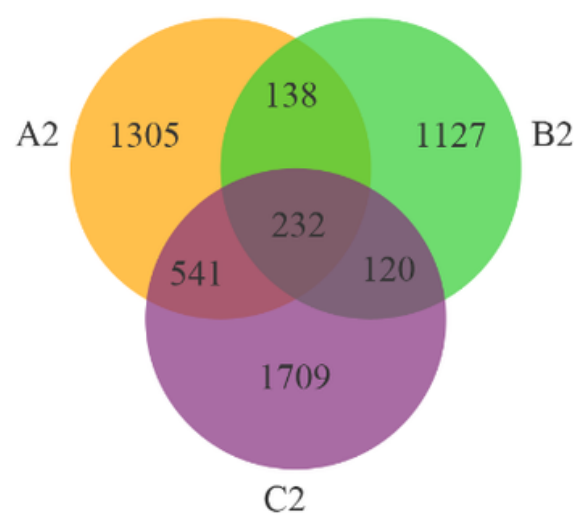

(f)

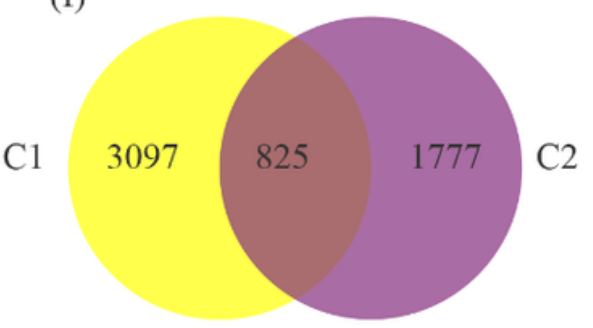

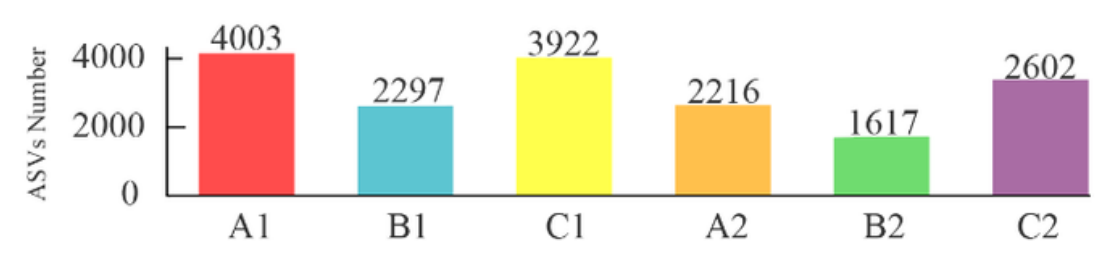

\section{Figure 2}

Number of sediment fungal ASVs in each sampling site, specific to a sampling site, or shared by two or three sampling sites. The number of ASVs within each sampling site was calculated after merging the sequences obtained from the three replicates from each sampling site, which were analysed by high-throughput sequencing after PCR. A1 and A2 were NPSP tributary sites, B1 and B2 were non-NPSP mainstream sites, and C1 and C2 were NPSP mainstream sites.
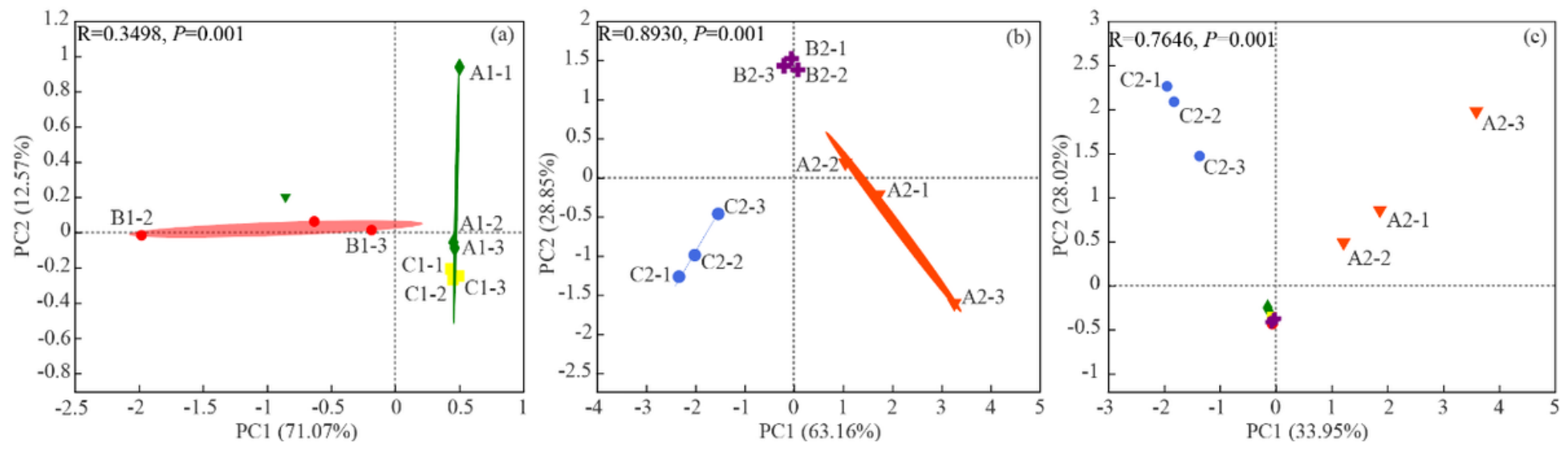

Figure 3 
PCA of the sediment fungal community at each sampling site.
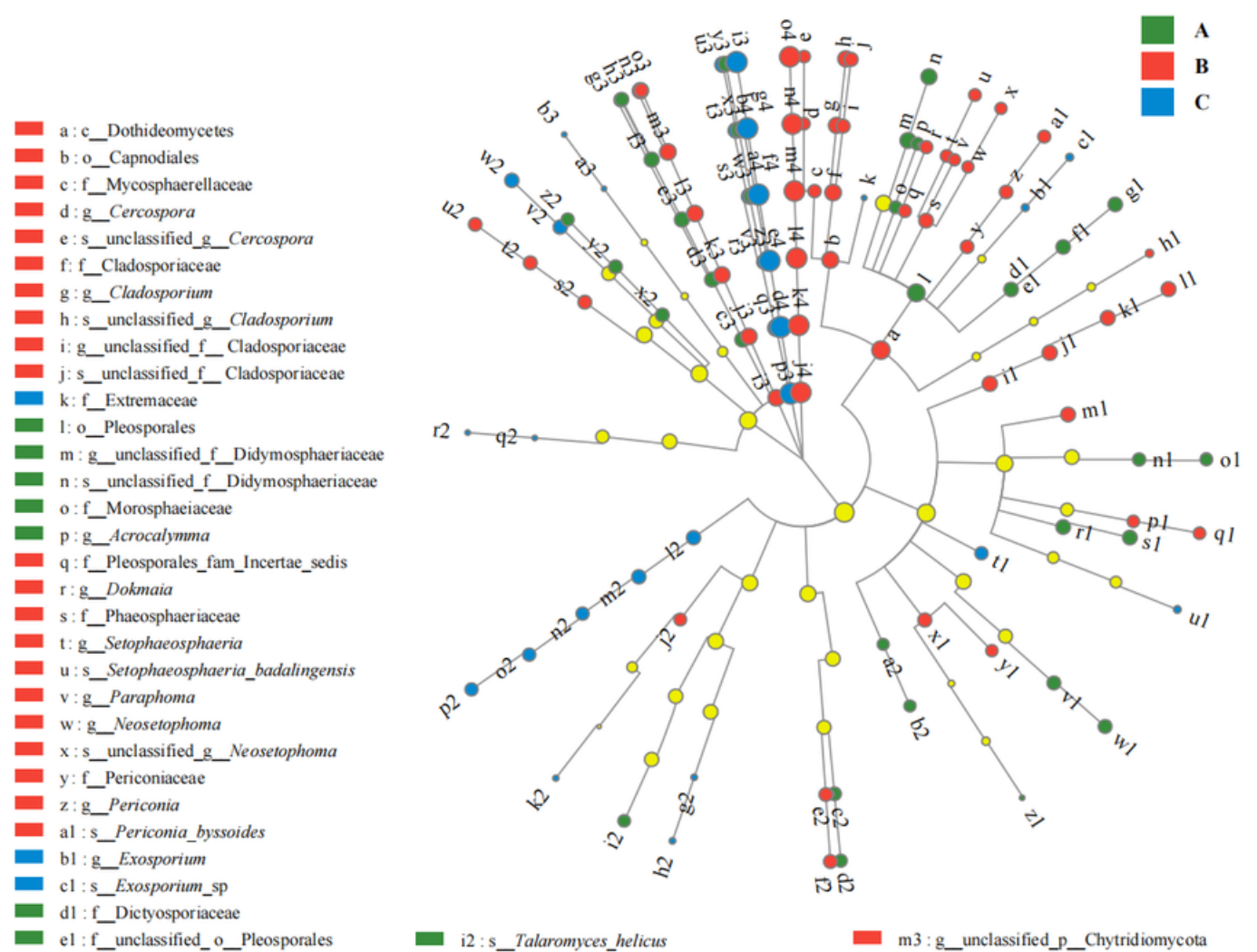

- - Pleosporales

- g1:s_unclassified_o_Pleosporales

hl : s_Aureobasidium_leucospemi

il : o_Glomerellales

- j1: f_Plectosphaerellaceae

k1:g_Plectosphaerella

- $11:$ s_unclassified_Plectosphaerella

ml : f_Nectriaceae $^{-}$

$\mathrm{nl}: \mathrm{g}$ Emericellopsis

ol : s_unclassified_Emericellopsis

- pl:g_Claviceps

- q1:s_Claviceps_sorghicola

rl:f_Hypocreaceae

sl:g Trichodermo

$\mathrm{tl}$ : o_Microascales

ul : s_Acaulium_sp

v1:g_Podospora

wl : s_Podospora_communis

- xl:o_Xylariales

yl : f Apiosporaceae

zl : s_unclassified_g_Microdochium

a2:o_Trichosphaeriales

b2:f Trichosphaeriaceae

c2:g_Ciboria

$\mathrm{d} 2$ : s_Ciboria shiraiana

- 2 : g_Botrytis

f2: s_unclassified_g_Botrytis

g2: $\mathrm{g}$ Phialosimple.

h2:s_Phialosimplex_sp

\begin{tabular}{|c|c|}
\hline - & i2:s_Talaromyces_helicus \\
\hline 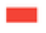 & j2:o_Chaetothyriales \\
\hline & k2: s_Exophiala_oligosperma \\
\hline & $12:$ c_Saccharomycetes \\
\hline a & $\mathrm{m} 2: \mathrm{o} \_$Saccharomycetales \\
\hline ¿ & $\mathrm{n} 2$ : $\mathrm{f} \_$Saccharomycetales_fam_Incertae_sedis \\
\hline G & o2: g_Candida \\
\hline - & $\mathrm{p} 2: \mathrm{s}$ _Candida_sake \\
\hline & $\mathrm{q} 2$ :f_Inocybaceae \\
\hline a & $\mathrm{r} 2: \mathrm{g}$ Inocybe \\
\hline 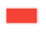 & s2 : f_Rhynchogastremataceae \\
\hline & $\mathrm{t} 2: \mathrm{g} \_$Papiliotrema \\
\hline 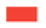 & u2 : s_Papiliotrema flavescens \\
\hline & v2:g_Tausonia \\
\hline & w2:s_Tausonia_sp \\
\hline & $\mathrm{x} 2: 0 \_$Trichosporonales \\
\hline & y2:f Trichosporonaceae \\
\hline ש & $\mathrm{z} 2: \mathrm{g}$ Apiotrichum \\
\hline & a3:g_Slooffia \\
\hline & b3 : s_Slooffia_cresolica \\
\hline & c3 : c_unclassified_p_Basidiomycota \\
\hline 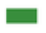 & d3 : o_unclassified_p_Basidiomycota \\
\hline & e3 : f_unclassified_p_Basidiomycota \\
\hline - & f3: g_unclassified_p_Basidiomycota \\
\hline$\square$ & g3 : s_Basidiomycota_sp \\
\hline - & h3 : s_unclassified_p_Basidiomycota \\
\hline- & i3 : p_Chytridiomycota \\
\hline 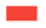 & j3 : c_unclassified_p_Chytridiomycota \\
\hline - & k3 : o_unclassified_p_Chytridiomycota \\
\hline & $13: f \_$unclassified_p_Chytridiomycota \\
\hline
\end{tabular}

m3: g_unclassified_p_Chytridiomycota

n3:s_unclassified_p_Chytridiomycota

- $03:$ s_Chytridiomycota_sp

[ p3: p_Rozellomycota

- $\mathrm{q} 3$ : c__Rozellomycota_cls_Incertae_sedis

- $13: 0$ B Branch02

s3: f_unclassified_o_Branch02

- $13: \mathrm{g}$ unclassified_o Branch02

u3 : s_Branch02_sp

v3:0 GS11

w3 : f_unclassified_o_GS11

- 3 : $: \mathrm{g}$ _unclassified_o_GS11

y3:s_GS11_sp

23:0_Branch03

a : f_unclassified_o_Branch03

b4: g unclassified o B Branch03

c $4:$ s_Branch03_sp

d4: c_unclassified_p_Rozellomycota

- $4:$ : o_unclassified_p_Rozellomycota

- $\mathrm{f} 4$ : $\mathrm{f}$ _unclassified_p_Rozellomycota

- 4 : g_ unclassified_p_Rozellomycota

[ 4 : s_unclassified_p_Rozellomycota

- i4:s_Rozellomycota_sp

- j4:p_unclassified_k_f Fungi

- $k 4: \mathrm{c} \_$unclassified_k_Fungi

14:0 unclassified $k$ Fungi

m $4: \mathrm{f}$ _ unclassified_k_Fung

- $\mathrm{n} 4: \mathrm{g}$ __ unclassified_k_Fungi

04 : s___unclassified_k_Fungi

Figure 4

Cladogram of the sediment fungal community structure at each sampling site (LAD score=3). 


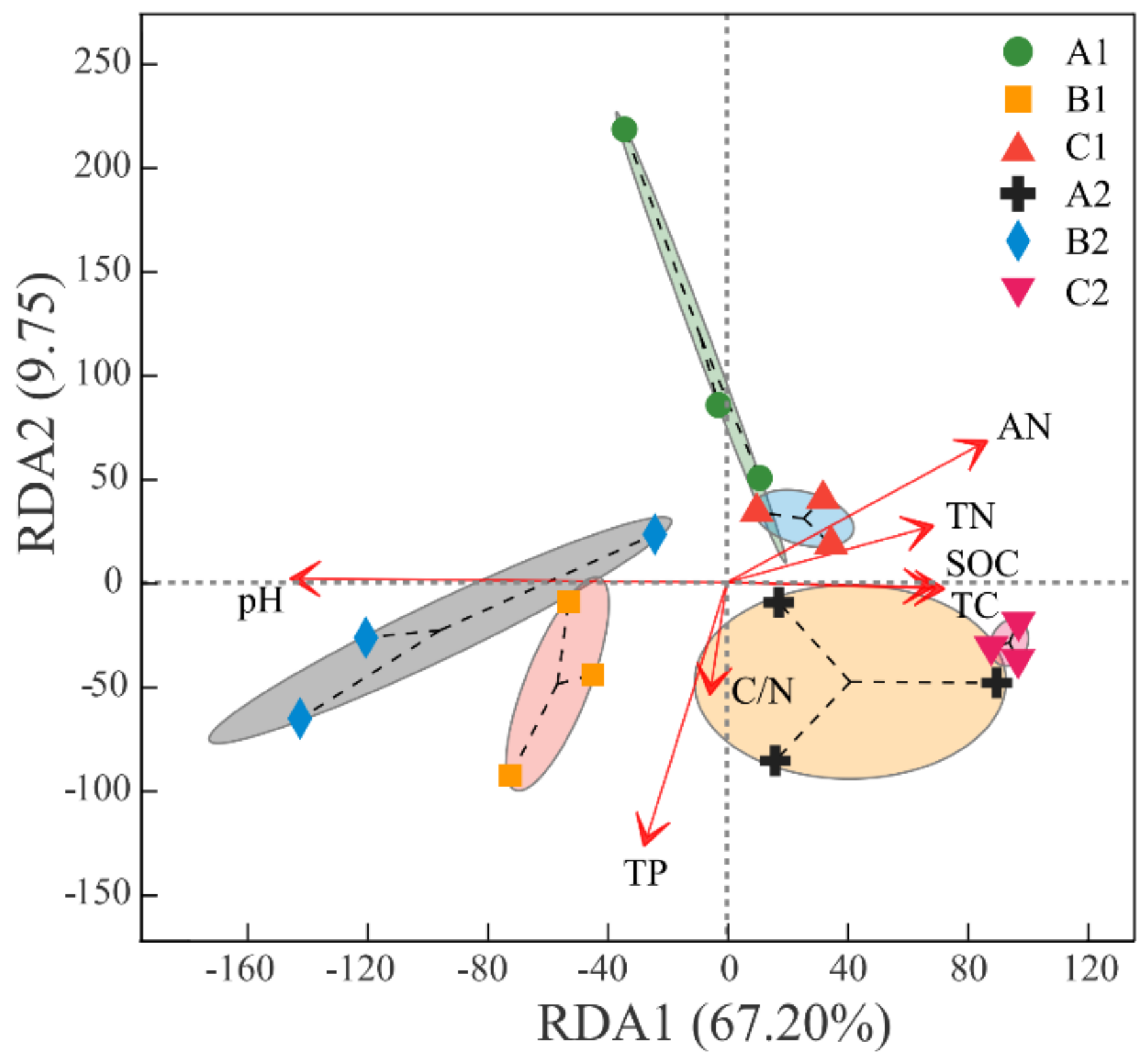

\section{Figure 5}

Redundancy analysis (RDA) of the sediment fungal community in relation to environmental factors. Sediment samples: red circles $A 1$, blue triangles $B 1$, green diamonds $C 1$, yellow square $A 2$, purple cross pattern $B 2$, red inverted triangles $\mathrm{C} 2$; arrows indicate the influence of environmental factors. The angle between sites and environmental factors indicates the direction of the correlation between them (acute angle, positive correlation; obtuse angle, negative correlation; right angle, no correlation). The vertical projection was drawn from different samples, and the closer the projection point was, the higher the influence of the environmental factor on the sample.

\section{Supplementary Files}

This is a list of supplementary files associated with this preprint. Click to download. 
- Supplmentarymaterials.docx

Page 23/23 